\title{
AORTO-PULMONARY FISTULA DUE TO FAILURE OF AN IVALON GRAFT FOR COARCTATION OF THE AORTA
}

\author{
BY \\ M. G. DAVEY* \\ From the Thoracic Surgical Unit, Royal Adelaide Hospital, Adelaide, Australia
}

In 1956 Case 1 , a clerk then 30 years of age, presented with recent mild dyspepsia. He was an active man who played competition tennis regularly. His abnormally high arterial pressure had been noted some years before; on this occasion examination also disclosed coarctation of the aorta with a brachial arterial pressure of $160 / 100 \mathrm{~mm}$. Hg.

On August 16, 1956, the coarcted segment was resected and replaced by a graft made of three layers of Ivalon sponge $\dagger$ compressed to $\frac{1}{8}$ inch thickness: this was $1 \frac{1}{2}$ inches long and $\frac{5}{8}$ inch in diameter. The patient made an uncomplicated recovery but the brachial arterial pressure was little reduced.

Twelve months later a routine chest radiograph revealed dilatation of the descending aorta at the level of the graft. At thoracotomy on August 30, 1957 , this was found to be an aneurysm of the graft, about 2 inches in diameter. The aneurysm was side-clamped and a redundant portion resected: the graft was then refashioned by a longitudinal suture and reinforced by wrapping round it a many-tailed bandage of nylon filter cloth (Fig. 1). While dissection was made difficult by adhesions it was not necessary to cross-clamp the aorta during this procedure. The patient made an uncomplicated recovery.

The portion of the graft removed had a superficial macroscopic resemblance to aorta. On microscopy scattered areas of irregular honeycomb material could be seen (presumably Ivalon) surrounded by a marked foreign body reaction (Fig. 2).

He remained well and under regular medical supervision until October, 1961, when he suddenly coughed up about $250 \mathrm{ml}$. of bright blood. On admission to the Repatriation General Hospital, Adelaide, no changes in cardiovascular signs and no abnormalities in systemic examination were found. A chest radiograph was normal ; a barium

* Now National Heart Foundation of Australia research fellow, Department of Medicine, University of Adelaide, Australia.

† Formalized polyvinyl alcohol sponge. meal suggested that a duodenal ulcer was present. In the following 10 weeks he had five further haemoptyses, the largest being of $600 \mathrm{ml}$. Investigations before and after transfer to this hospital, including several chest radiographs, two bronchoscopies, and coagulation studies, failed to reveal either the source of or reason for the bleeding. No pain or other symptoms were associated with it, although on one occasion he claimed to feel that the blood he coughed up came from the left side of the chest. It was finally decided that a fistulous connexion between the grafted area and the lung was the only possible explanation for the haemorrhages.
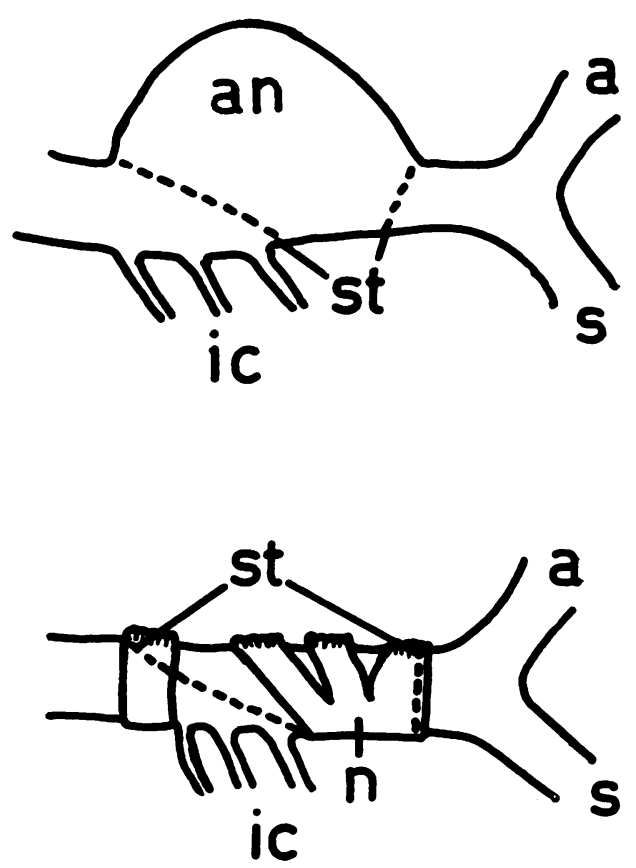

FIG. 1. Diagram illustrating repair of aneurysmal graft : $a=$ aorta ; $a n=$ aneurysm ; ic=intercostal arteries: $n=n y l o n$ reinforcement ; $s=$ subclavian artery ; $s t=$ suture lines. 


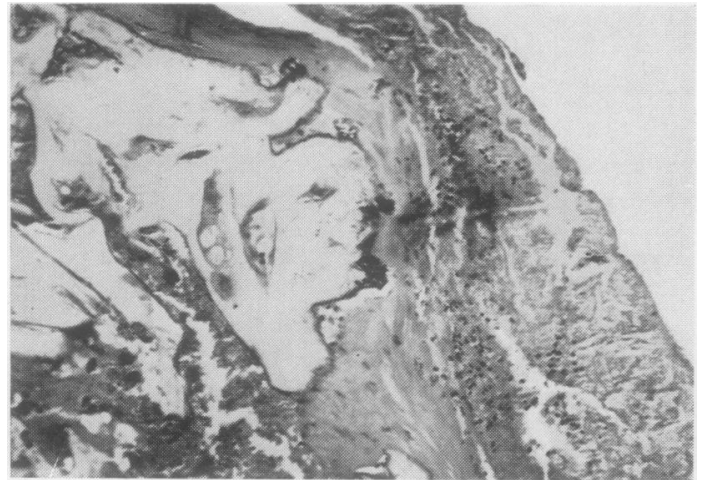

FIG. 2. Case 1. Portion of graft excised in 1957 showing fragments of Ivalon with marked foreign body reaction (left) and organizing thrombus on the endothelial surface (right). $H$. and E., $\times 250$.

At thoracotomy on December 20, 1961, a left atrial-femoral artery bypass was established (as described by Cooley, DeBakey, and Morris (1957)), and the lung, which was closely adherent, was stripped from the area of the graft. Superficially this appeared intact; closer inspection revealed erosion of the nylon covering and a paper-thin area near the upper anastomosis which very shortly ruptured. The aorta was cross-clamped, the blood pressure being controlled by adjustment of flow in the bypass, and the area was replaced by a prosthesis of woven crimped Teflon.*

Close inspection of the lung revealed a small bronchus opening on to the raw surface, evidence that the haemoptyses had followed ruptures of the weakened graft. The resected portion resembled the wall of an atheromatous aneurysm with portions of synthetic material embedded in the fibrous media (Fig. 3).

\section{Discussion}

Aneurysm formation has been reported after the use of this type of aortic prosthesis. In an experimental series, Harrison (1957) reported such complications in eight out of nine grafts of the thoracic aorta and two out of nine grafts of the abdominal aorta in dogs. He demonstrated almost complete absorption of the material after 180 days and its replacement by a wall of fibrous tissue of negligible tensile strength. Pratt (1958) cited the failure of 12 out of 18 aortic grafts in dogs.

In this clinic only one other patient has had an Ivalon prosthesis placed in the aorta. Case 2, a

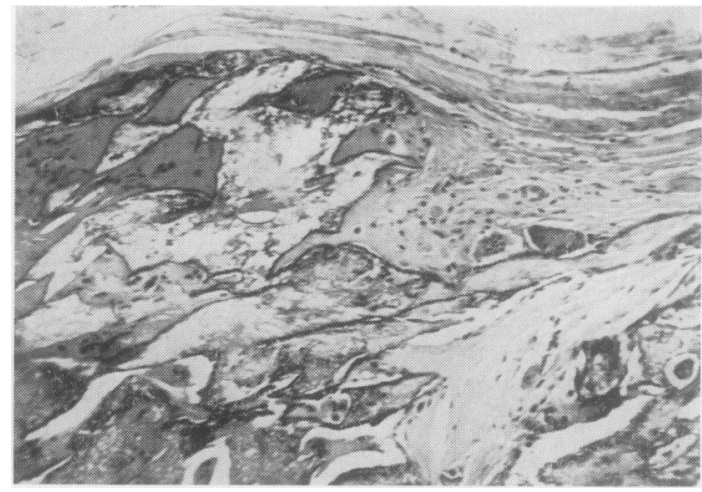

FIG. 3. Case 1. Portion of graft excised in 1961 showing portion of a subendotheiial atheromatous plaque (left) and fragments of nyion deep to this: a moderate foreign body reaction is evident. $H$. and $E ., \times 250$.

girl aged 19, presented in 1956 with signs of coarctation and had the affected segment replaced by a graft also $1 \frac{1}{2}$ inches long. Dilatation of this became radiologically evident four years later, and in April, 1961, it was removed and a Teflon graft inserted. Left atrial-femoral artery bypass was again used in the second procedure.

The segment removed at this operation had the appearance of an atheromatous aneurysm. There was no elastic tissue, some bone formation, and an active inflammatory infiltrate in its wall. No trace of the prosthesis was found (Fig. 4).

Thus our small experience supports the conclusion of Harrison (1957) that Ivalon is an unsuitable material to be used as a vascular prosthesis in large unsupported vessels. Trippel,

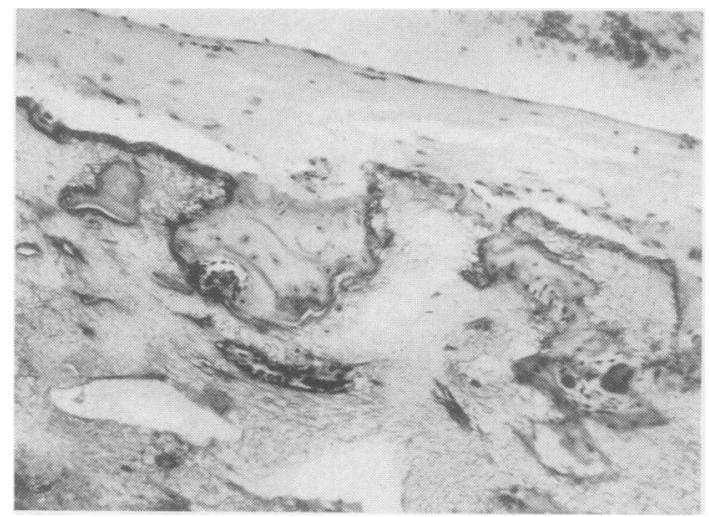

FIG. 4. Case 2. Bone formation in a portion of the wall of the excised aneurysm. $H$. and $E$., $\times 250$. 
Shields, Bernhard, Benvenuto, and Lewis (1960) have advocated the use of a laminated prosthesis of Ivalon reinforced with coarse nylon mesh for this purpose. Of 40 such grafts in the thoracic aortas of dogs, 33 remained patent and undilated at intervals of one week to 28 months, while thrombosis had occurred in three, dissection in one, dilatation in one, and bleeding related to infection in one. Two of seven unreinforced grafts observed for 18 to 22 months showed dilatation, and one other had ruptured. In patients, one graft out of ten had thrombosed and one had bled; none showed dilatation after observation for three to 20 months.

These observations have not been made over a sufficiently long period to exclude the complete absorption of the graft and dilatation or rupture of the remaining fibrous tube, which we have seen in our patients, and which is most unlikely to occur when an inert, unabsorbable material such as Teflon is used. Harrison (1958) has demonstrated that this material loses none of its tensile strength after two years, while Edwards (1959) described the mechanical advantages of the crimped woven Teflon tubes which we have come to regard as the most satisfactory prosthesis at present available.

The reparative procedure undertaken in 1957 and its consequence suggest that the development of any complication in a patient with an Ivalon graft is an indication for the complete replacement of the graft ; this can be done at leisure if bypass facilities are available. It would be presumptuous to hope that aortic rupture would present in so benign a fashion on another occasion.

\section{SUMmary}

A case is presented in which the replacement of a coarctation of the aorta by an Ivalon graft was followed by aneurysm formation and, subsequent to its repair, by leakage of the patched graft into the lung. The use of Ivalon for vascular prostheses and the surgical treatment of complications of its use are discussed. Teflon appears to be the most suitable material generally available for vessel grafts at present on account of the slight tissue reaction to it and its retention of tensile strength for long periods.

Operations described were performed by $\mathrm{Mr}$. H. D. Sutherland, for whose criticism and permission to publish I am grateful. The first patient was also under the care of Professor H. N. Robson, by whom he was referred to the Thoracic Unit. I thank the Medical Superintendent of the Royal Adelaide Hospital and the Chairman of the Repatriation Commission for their permission to publish; Mr. J. P. Richardson and Dr. J. L. Waddy for encouragement and advice; Dr. R. T. W. Reid for histological reports; and Mr. W. Nolan for photomicrographs.

\section{REFERENCE;}

Cooley, D. A., DeBakey, M. E., and Morris, G. C. (1957). Ann. ne. Surg., 146, 473.

Edwards, W. S. (1959). Surgery, 45, 298.

Harrison, J. H. (1957). Ibid., 41, 729.

- (1958). Amer. J. Surg., 95, 3, 16.

Pratt, G. H. (1958). Surg. Gynec. Obstet., 107, 107.

Trippel, O. H., Shields, T. W., Bernhard, V. M., Benvenuto, R., and Lewis, F. J. (1960). Ann. Surg., 151, 216. 